\title{
A new species of highland vampire crab (Crustacea: Brachyura: Sesarmidae: Geosesarma) from Serian, Sarawak
}

\author{
PETER K. L. NG ${ }^{1} \&$ JONGKAR GRINANG ${ }^{2,3}$ \\ ${ }^{1}$ Lee Kong Chian Natural History Museum, Faculty of Science, National University of Singapore, Kent Ridge, Singapore 119260, \\ Republic of Singapore \\ ${ }^{2}$ Institute of Biodiversity and Environmental Conservation, Universiti Malaysia Sarawak, 94300 Kota Samarahan, Sarawak, Malaysia \\ ${ }^{3}$ Corresponding author. E-mail: gjongkar@unimas.my
}

\begin{abstract}
A new species of semiterrestrial highland vampire crab of the family Sesarmidae, Geosesarma larsi n. sp., is described from western Sarawak. This brings the number of Bornean Geosesarma species to 12. Geosesarma larsi n. sp. is distinguished from congeners by the structures of the carapace, third maxilliped exopod and gonopods, as well as the proportions of its ambulatory legs. The colour pattern in life is also strikingly different from allied species. Notes on its ecology are provided and conservation threats briefly discussed.
\end{abstract}

Key words: semiterrestrial crab, taxonomy, Borneo, Malaysia, phytotelm

\section{Introduction}

The semiterrestrial sesarmids of the genus Geosesarma De Man, 1892, popularly called vampire crabs, are now represented by 58 species from Southeast Asia and adjacent areas ( $\mathrm{Ng}$ et al. 2008, 2015; Naruse \& Jaafar 2009; Schubart \& Ng 2014; Ng 2015, 2017; Manuel-Santos et al. 2016). Ng (2015) reviewed the taxonomy of the genus in Borneo, recognizing 11 species, all of which are endemic to the island. Of these, four species are currently known from the East Malaysian state of Sarawak: G. bau Ng \& Grinang, 2004, G. gracillimum (De Man, 1902), G. katibas Ng, 1995, and G. sarawakense (Serène, 1968).

A strikingly coloured new species crab is here described from a mountain in the division of Serian in western Sarawak, Malaysia. The new species is diagnosed and compared with allied congeners.

Material examined is deposited in the Sarawak Biodiversity Centre (SBC), Kuching, Sarawak, Malaysia; and the Lee Kong Chian Natural History Museum (LKCNHM), National University of Singapore. Measurements provided, in millimetres, are of the maximum carapace width and length, respectively. The terminology used follows $\mathrm{Ng}$ (1988) and Davie et al. (2015).

\section{Taxonomy}

Family Sesarmidae Dana, 1851

Genus Geosesarma De Man, 1892

Type species. Sesarma (Geosesarma) nodulifera De Man, 1892, subsequent designation by Serène \& Soh (1970). 